$\begin{array}{lll}\text { Jurnal ReviewPendidikan dan Pengajaran } & \begin{array}{l}\text { Submitted : 11/12/2019 } \\ \text { http://journal.universitaspahlawan.ac.id/index.php/jrpp } \\ \text { Volume 2 Nomor 2, Desember 2019 }\end{array} & \begin{array}{l}\text { Reviewed :15/12/2019 } \\ \text { Pccepted :20/12/2019 } \\ \text { P-2655-710X e-ISSN 2655-6022 }\end{array} \\ & \text { Published:28/12/2019 }\end{array}$

Yenni Sri Utami ${ }^{1}$
Ida Wiendijarti
Sigit Tri Pambudi $^{2}$

\section{PENGEMBANGAN KURIKULUM PROGRAM STUDI HUBUNGAN MASYARAKAT DI ERA REVOLUSI INDUSTRI 4.0}

\title{
Abstrak
}

Keberadaan Program Studi Hubungan Masyarakat di Jurusan atau Departemen Ilmu Komunikasi diharapkan mampu memenuhi kebutuhan industri akan profesional di bidang Hubungan Masyarakat, yang mampu menjalin hubungan baik antara perusahaan, pemerintah dan masyarakat, Mengembangkan Hubungan Masyarakat Kurikulum diharapkan dapat memenuhi kebutuhan persiapan manajemen komunikasi untuk perusahaan, lembaga pemerintah dan masyarakat yang mampu meningkatkan tata kelola perusahaan, lembaga pemerintah dan masyarakat di era informasi dan keterbukaan saat ini. Selain itu, juga mendukung Peraturan Menteri Komunikasi dan Informasi Republik Indonesia Nomor 12 Tahun 2015 tentang standar kompetensi Posisi Fungsional Lembaga Hubungan Masyarakat. Penelitian ini bertujuan untuk mengetahui kelayakan kurikulum yang diterapkan dalam proses pembelajaran di Program Studi Hubungan Masyarakat dalam menghadapi Revolusi Indonesia 4.0 yang ditandai dengan persaingan yang ketat dan arus informasi yang cepat di semua sektor. Profesional Hubungan Masyarakat dituntut memiliki daya saing yang kuat untuk dapat menyelaraskan diri dengan profesional Hubungan Masyarakat negara lain. Inovasi adalah kunci untuk meningkatkan produktivitas berkelanjutan, yang pada gilirannya dapat mempercepat pertumbuhan ekonomi bangsa. Untuk meningkatkan kualitas dan kuantitas inovasi di era Revolusi Industri 4.0, universitas perlu mengarahkan kembali kurikulum agar tetap relevan dengan zaman. Data yang diperoleh dari penelitian diharapkan dapat memberikan informasi dan input pada bahan yang dapat mendukung proses pembelajaran, sehingga hal-hal yang perlu ditangani dan ditingkatkan dapat diidentifikasi. Penelitian ini menggunakan pendekatan evaluatif dengan metode studi kasus, yang bertujuan untuk menggambarkan situasi atau mencari fakta dan fakta secara faktual.

Kata kunci: hubungan masyarakat, kurikulum, Revolusi Industri 4.0

\footnotetext{
${ }^{1}$ Ilmu Komunikasi, Fakultas Sosial dan Ilmu Politik, Universitas Pembangunan Nasional "Veteran" Yogyakarta yenni.sriutami@upnyk.ac.id

${ }^{2}$ Ilmu Komunikasi, Fakultas Sosial dan Ilmu Politik, Universitas Pembangunan Nasional "Veteran" Yogyakarta idawiendijarti@yahoo.co.id

${ }^{3}$ Ilmu Komunikasi, Fakultas Sosial dan Ilmu Politik, Universitas Pembangunan Nasional "Veteran"

Yogyakarta

mrsgt_upnyk@yahoo.com
} 


\section{Abstract}

The existence of the Public Relations Study Program in the Department of Communication is expected to be able to meet the industry's need for professionals in the field of Public Relations, who are able to establish good relations between companies, government and society, Developing a Public Relations curriculum is expected to be able to meet the needs of communication management preparation for companies, government agencies and a society that is able to improve corporate governance, government agencies and the public in the current era of information and openness. In addition, it also supports the Regulation of the Minister of Communication and Information of the Republic of Indonesia, Number 12 of 2015 concerning the competency standard of the Functional Position of Public Relations Institution. The research is intended to determine the feasibility of the curriculum applied in the learning process in the Public Relations Study Program in the face of the Indonesian Revolution 4.0 which is characterized by intense competition and rapid information flow in all sectors. Public Relations Professionals are required to have strong competitiveness to be able to align themselves with other countries' Public Relations professionals. Innovation is the key to increasing sustainable productivity, which in turn can accelerate the nation's economic growth. To improve the quality and quantity of innovation in the Industrial Revolution 4.0 era, universities need to re-orient the curriculum so that it remains relevant to the times. The data obtained from research are expected to be able to provide information and input on materials that can support the learning process, so that things that need to be addressed and improved can be identified. This study uses an evaluative approach with a case study method, which aims to describe the situation or look for facts and facts factually.

Keywords: public relations, curriculum, Industrial Revolution 4.0 


\section{PENDAHULUAN}

Hubungan Masyarakat (Humas) asebagai suatu profesi di era 4.0 saat ini, nampknya harus bersaing ketat di berbagai bidang baik industri maupun pemerintahan, apalagi pekerjaan seorang Humas sangat berkaitan dengan perubahan arus informasi dan perkembangan teknologi komunikasi yang semakin pesat. Kreativitas dan inovasi memiliki peran penting dalam upaya meningkatan produktifitas secara kontinyu, sehingga mampu meningkatkan perekonomian bangsa dengan cepat. Sebagai upaya dalam meningkatkan kualitas dan kuantitas inovasi di era Revolusi Industri 4.0, dibutuhkan peran perguruan tinggi dalam melakukan reorientasi kurikulum sebagai upaya untuk menyesuaikan dan mengikuti perkembangan zaman. Pendidikan tinggi di Indonesia pada dasarnya memiliki tujuan untuk mentransformasi masyarakat menjadi sumber daya manusia yang inovatif dan adaptif. Oleh karena itu agar peguruan tinggi mampu menghasilkan tenaga kerja yang memiliki kompetensi yang siap menghadapi industri kerja yang senantiasa berkembang seiring dengan perkembangan teknologi, keahlian kerja, kemampuan beradaptasi dan pola pikir yang semakin dinamis.

Program Studi Hubungan Masyarakat di jurusan Komunikasi merupakan upaya untuk memenuhi tuntutan industri yang terus berkembang, sehingga keberadaan Prodi Hubungan Marakat di jurusan Komunikasi diharapkan bisa memenuhi kebutuhan industri akan tenaga profesional di bidang Hubungan masyarakat. Hadirnya Prodi Hubungan Masyarakat di jurusan Komunikasi membuat UPN "Veteran" Yogyakarta, menjadi institusi yang menyebarluaskan ilmu pengetahuan di bidang manajemen komunikasi, sehingga mampu mendukung dunia industri yang membutuhkan relasi yang baik antara perusahaan, pemerintah dan masyarakat

Transformasi Hubungan Masyarakat (Humas) menghadapi era revolusi Industri 4.0 merupakan suatu hal yang pasti dan harus dihadapi, sehingga seorang profesioan humas harus melakukan beberapa hal seperti

Pertama, Kompetensi. Kehadiran internet telah mengubah teknologi analog menjadi digital sehingga seorang profesional humas harus memiliki seperangkat ketrampilan untuk melakukan pembaharusan serta memiliki kompetensi teknologi maupun non-teknologi yang sesuai dibidangnya. Pada era industri 4.0, dibutuhkan praktisi Humas yang memiliki fleksibilitas dan mobilitas yang tinggi, kompten mengoperasikan teknologi digital, mampu menganalisis, kemampuan verbal baik tertulis maupun lesan, mampu menjalin relasi, selalu ingin mencari informasi aktual serta memiliki spesialisasi.

Kedua, Personalisasi Konten. Seorang profesional Humas harus memiliki kreatifikas dalam menyusun pesan agar publik yang menjadi sasaran merasa dihargai,. Sebaiknya tidak membuat pesan yang digeneralisisr untuk semua segmen, tapi harus mampu berkomunikasi dengan publik secara personal dan menyesuaikan dengan segmen, sehingga mampu memberikan dampak yang maksimal.. Banyaknya beragam konten dan informasi yang bisa 
diperoleh dengan mudia saat ini, menuntu seorang Humas harus lebih selektif melihat siapa target audience-nya, media yang digunakan, serta konten yang relevan dengan mereka. Apabila seorang Humas menghadapi situasi krisis, maka dibutuhkan kompetensi dalam manajemen reputasi, dan membangun sebuah brand, atau seorang Humas di era 4.0 harus mampu menjadi penyedial dan penyebar konten terhadap publiknya.

Ketiga, Kreatif dan Memahami Global Trend. Perkembangan teknologi dari fenomena video $360 \mathrm{CNN}$, live streaming, drone hingga mixed reality dari Windows, nampaknya telah mengombinasikan digital teknologi dalam melakukan peran fungsi Humas diera 4.0. Keempat, Integritas. Terjangan arus polemik isu dari hoax hingga fake news, nampaknya menjadi tantangan tersendiri bagi humas. Seorang Humas seharusnya tetap memiliki tata kelola (Good Governance), akuntabel, transparan dalam menjawab bukan hanya terhadap stakeholders saja , namun bagi seluruh warga negara. Kelima, Kolaborasi. Seorang humas harus mampu berkolaborasi dengan siapa saja, mengingat di era digital ini, seorang humas harus memahami dan mampu bekerjasama dan menjalin relasi dengan digital content creator, videograpgher, infographic, Ads people, brand people hingga marketing, hal ini penting untuk memperoleh efek yang optimal. Hal ini mengingat peran dan fungsi Humas adalah membangun trust dan reputasi melalui branding.

Humas 1.0 merupakan era ketika praktisi humas masih bertugas secara tradisional, dimana humas masih bekerja dengan melakukan monitoring secara manual setiap hari, dengan memantau berbgai informasi dari media massa baik media cetak maupun media elektronik seperti koran, majalah, hingga televisi.

Humas 2.0 merupakan era kehadiran media online. Media seperti New York Times, The Economist, Kompas, hingga Tempo beralih ke platfrom digital. Pada era digital dimulailah arus informasi lalu-lalang begitu pesat karena pengelola media bisa membuat berita kapan saja, di mana saja, dan tentang apa pun. Apabila di era Humas 1.0, wartawan terpaku dengan deadline di sore hari, maka pada era digital, setiap waktu adalah deadline, karena semua saling berlomba membuat informasi dan menyebarkan secara cepat. Sedangkan pada era Humas 3.0 merupakan era anomali di mana media sosial menjadi media yang dipercaya masyarakat. Jika pada era sebelumnya hanya wartawan yang bisa membuat berita, maka eranya berubah. Siapa pun bisa membuat dan mengunggah dan menyebarkan berita. Media seperti Facebook, Twitter, Instagram, YouTube, hingga blog menjadi digital platform.Seorang Humas profesional dituntut tidak hanya memonitor media -offline dan online, namun juga media sosial, karena informasi atau berita baik yang positif maypun negatif bisa datang kapan saja, oleh siapa saja.

Pada Humas 4.0 Saat ini kehadiran artificial intelligent (AI) dan era big data memang dampaknya belum terasa saat ini. Namun, kehadiran robot adalah fenomena yang sudah kita hadapi, dimana robot memiliki kemampuan menulis artikel di media dan 
membantu menulis, mencari bahan, atau apapun. Jika pada era sebelumnya tugas humas adalah 24x7 jam, namun di era Humas 4.0 menjadi $7 \times 1.440$ menit, artinya bahwa humas harus bekerja setiap menit, karena Humas harus selalu memiliki kasadaran atas berbagai situasi yang terjadi, dimana humas bukan hanya berkompetisi dengan humas lintas negara, namunsaat ini humas berkompetis dengan AI dan robot!

Pengembangang kurikulum pada Program Studi Hubungan Masyarakat diharapkan mampu memenuhi kebutuhan penyiapan manajemen komunikasi bagi perusahaan, instansi pemerintah dan masyarakat yang diharapkan akan meningkatkan tata kelola perusahaan, instansi pemerintah dan masyarakat di era informasi dan keterbukaan sekarang ini. Hal ini juga didasarkan pada pelaksanaan program SKB 3 Menteri yaitu Kementerian Dalam Negeri Nomor : 41 Tahun 2007, Kementerian Kominfo Nomor : 373/M.KOMINFO/08/2007, dan meneg PAN RB Nomor : KB/01/M.PAN/08/2007. Untuk merevitalisasi kehumasan dalam rangka berupaya menyempurnkan proses kerja kehumasan agar lebih hidup dan mampu menjawab tatangan di era keterbukaan informasi.

Kelayakan kurikulum yang diterapkan pada proses pembelajaran di Program Studi Hubungan Masyarakat dalam menghadapi Revolusi Indutri 4.0, sangat berkaitan dengan perubahan arus informasi dan perkembangan teknologi komunikasi yang semakin pesat. Kreativitas dan inovasi memiliki peran penting dalam upaya meningkatan produktifitas secara kontinyu, sehingga mampu meningkatkan perekonomian bangsa dengan cepat. Sebagai upaya dalam meningkatkan kualitas dan kuantitas inovasi di era Revolusi Industri 4.0, dibutuhkan peran perguruan tinggi dalam melakukan reorientasi kurikulum sebagai upaya untuk menyesuaikan dan mengikuti perkembangan zaman. Pendidikan tinggi di Indonesia pada dasarnya memiliki tujuan untuk mentransformasi masyarakat menjadi sumber daya manusia yang inovatif dan adaptif.

\section{TINJAUAN PUSTAKA}

\section{Industri 4.0}

Revolusi industri 4.0 nampaknya telah mengubah pandangan dan persepsi masyarakat dengan memandang internet menjadi mesin pintar yang mampu menyalin semua hal secara virtual berbagai hal dari yang bersifat nyata sampai pada melakukan pengambilan keputusan yang berkembang secara terdesentralisasi. Perubahan suatu sistem yang secara nyata dan riil mampu berkolaborasi dan berinteraksi dengan sesama individu yang lain, kemudian berubah dan seemuanya diaktifkan oleh internet of things (IoT). Berbagai pro dan kontra terkait dengan Dampak dari Industri 4.0 secara global mengalami perkembangan yang sangat cepat yang disebabkan oleh pembahasan intensif mengenai digitalisasi, Internet of things, dan sistem pengetahuan yang semakin maju (Vermesan, 2013). 
Berbagai pendapat pro dan kontra ini didukung karena adanya ketidakpastian mengenai strategi dalam memanfaatkan secara cepat inovasi teknologi sebagai upaya dalam memajukan berbagai aspek dalam kehidupan manusia.

Industri 4.0 yang dimulai tahun 2011 di Hanover Fair Jerman sebanranya merupakan upaya untuk melakukan pencegahan terhadap semakin tingginya kompetisi dari luar negeri, serta dalam upaya melakukan spesifikasi pada Industri Jerman dan Uni Eropa dari pasar internasional lainnya (Pascall, 2019). pemerintah Jerman berusaha untuk melakukan interfensi terhadap berbagai proses produksi untuk membantu pengambilan keputusan serta melakukan efisiensi dalam penggunaan mesin sebagai upaya untuk menminimalkan biaya produksi dan menambah daya saing industri Jerman. Beberapa hal yang mendasari mengapa Industri 4.0 memainkan peran strategis dan menjadi revolusioner di era teknologi informasi dan era keterbukaan saat ini. Pertama, Industri 4.0 mampu meminimalisir adanya beban tantangan yang ada dengan menjadikan perusahaan lebih fleksibel dan responsif terhadap trend bisnis, misal terjadinya volatilitas pasar yang semakin meningkat, semakin kecil siklus hidup terhadap suatu produk, lebih beragam varian suatu produk produki, dan alur distribusi yang semakin meluas. Kedua, Industri 4.0 membuat terjadinya perubahan dalam bidang perekonomian mengalami pembaharuan dan lebih dinamis.. Dimana dengan adanya teknologi modern seperti rantai digital, sistem cerdas, dan industri Internet diharapkan mampu mempercepat kreatifitas dan kebaruan dalam kegiatan usaha yang mampu dengan cepat diimplementasikan secara riil. Ketiga, menitikberatkan pada peran konsumen sebagai co-producer serta menempatkan konsumen pada berbagai bidang usaha. Personalisasi pada hasil produksi dalam rantai nilai suatu produk menjadi hal yang dianggap penting, serta dengan digitalisasi diharapkan mampu mendukung terlaksananya crowdsourcing. Dalam hal ini seorang karyawan akan ditugaskan di berbagai sisi yang membutuhkan bantuan, sehingga karyawan ditunutut memiliki keterampilan lebih dan fleksibel dalam mengelola proyek yang kompleks. Keempat, strategi industri 4.0 menjanjikan peningkatan kesejahteraan secara terus menerus dengan menggunakan teknologi modern dalam upaya memecahkan suatu masalah atas berbagai permasalahan yang berkaitan dengan energi, sumber daya, lingkungan sosial dan dampak ekonomi. Pemecahan masalah secara inovatif dapat menurunkan konsumsi energi, membantu perusahaan untuk tetap menstabilkan bisnisnya baik yang sudah ada maupun bisnis baru serta menggunakan teknologi baru yang dapat digunakan secara umum diberbagai tempat, berbagai variasi biaya baik yang tinggi mamupun yang dekat dengan pasar dengan menggunakan potensi tenaga kerja domestik. Kelima, industri 4.0 sebagai IoT, dimana kebradaan data dan layanan akan mengubah produksi masa depan, logistik dan proses kerja. (Acatech, 2014).

Dalam beberapa tahun terakhir ini, revolusi IoT tmenjadi terobosan baru yang mampu menghubungkan internet secara terintergrasi dengan teknologi lain seperti cara mempelajari mesin, sistem yang tertanam, dan serta jaringan nirkabel. Penelitian yang dilakukan oleh Eropa 
Kluster Internet of Things (IERC) menunjukkan bahwa IoT merupakan sesuatu yang terintegrasi dari Internet masa depan dan dapat dimaknai sebagai perkembangan infrastruktur jaringan global yang mampu melakukan konfigusai mandiri berdasarkan standar komunikasi dan interoperable protokol di mana fisik dan virtual menjadi suatu hal yang memiliki identitas, atribut fisik, dan kepribadian virtual dan menggunakan antarmuka cerdas, dan mulus terintegrasi ke dalam jaringan informasi (Vermesan, 2013). Berdasarkan hal ini atas dapat disimpulkan bahwa tujuan utama dari IoT adalah untuk menjadikan hal-hal yang sebelumnya tidak terhubung menjadi saling terhubung tanpa adanya batasan tempat, waktu, maupun birokrasi dengan siapa pun yang idealnya menggunakan jaringan dan layanan apa pun.

\section{Peran Hubungan Masyarakat (Public Relations)}

Public Relations memiliki peran penting dalam menjaga stabilitas organisasi dari krisis, reputasi yang terpelihara baik dan lingkungan kerja yang kondusif. Fungsi Public Relations secara manajerial adalah melakukan penilaian terhadap sikap publik, melakukan identifikasi terhadap berbagai kebijakan dan berbagai aturan baik terhadap perseorangan maupun organisasi untuk kepentingan public, serta melakukan perencanaan dan melaksanakan program kegiatan sebagai upaya untuk memperoleh pengertian serta dukungan publik (Cutlip, 2011). Peran Public Relations sebagai ujung tombak perusahaan terutama dalam menjaga dan memelihara citra, membuat perencanaan kampanye produk dan sebagainya. Public Relations menurut Institute Public Relations merupakan kegiatan yang terencana dan berkelanjutan untuk membentuk dan menjaga sikap baik dan pengertian antara organisasi dan publik (Acatech, 2014).

Berbagai kegiatan yang dilakukan Public Relations tidak hanya sebagai penerimaan masyarakat terhadap penerimaan atau popularitas, namun lebih menekankan pada sikap baik dan pengertian.. Beberapa kegiatan Public Relations yang dilakukani pada era revolusi industri 4.0, antara lain, Buzzer yaitu adanya Buzz marketing yang merupakan sebuah alternative dari periklanan tradisional dengan memanfaatkan influencer atau trend setter untuk menyebarkan berita mengenai suatu produk (Seitel, 2014), Buzzer merupakan istilah yang ditujukan pada para pelaku media sosial yang melakukan kegiatan word-of-mouth. Konsumen dengan pengalaman berbelanja yang mudah diingat, mereka cenderung akan menginformasikan kepada orang lain melalui media sosialnya tentang pengalaman tersebut, Pola komunikasi untuk wordof-mouth di era digital bisa dalam bentuk email, blog, situs review konsumen dan social networking service (SNS), yang telah menjadi media utama pertukaran berita dan pengalaman (Hirsch, 2018). Informasi yang berasal dari sumber non komersial biasanya lebih efektif dalam menghasilkan referensi untuk produk sekunder, karena mampu mengambil peran penting dalam pengambilan keputusan. dimana aspek yang disentuh oleh Word-of-mouth tidak hanya mampu membentuk sikap namun bisa juga mempengaruhi pengambilan keputusan pembelian, Media komunikasi untuk Word-of-mouth seperti email, blog, situs review konsumen dan SNS, 
nampaknya merupakan media utama dalam pertukaran berita dan pengalaman (Hirsch, 2018). Public Relations di era 4.0 dituntut untuk memiliki nilai lebih seperti mampu berperan aktif dan terlibat langsung dengan kelompok influencer baru, mampu menjalin hubungan dengan pelanggan secara langsung melalui jejaring sosial, wiki, komunitas mikromedia, forum online, grup dan blog.

Selain berbagai kegiatan di atas, kegiatan lain yang dilakukan adalah oleh Public Relations adalah aktif di media sosial untuk menyebarkan pesan-pesan kampanye kehumasan, hal ini mengingat bahwa media sosial memiliki keunggulan antara lain biayanya yang murah karena hanya menggunakan internet dan web (Robert, 2008).

\section{METODE}

Penelitian ini menggunakan metode wawancara, Focus Group Discussion (FGD) dan tinjauan pustaka melalui tahapan-tahapan sebagai berikut:

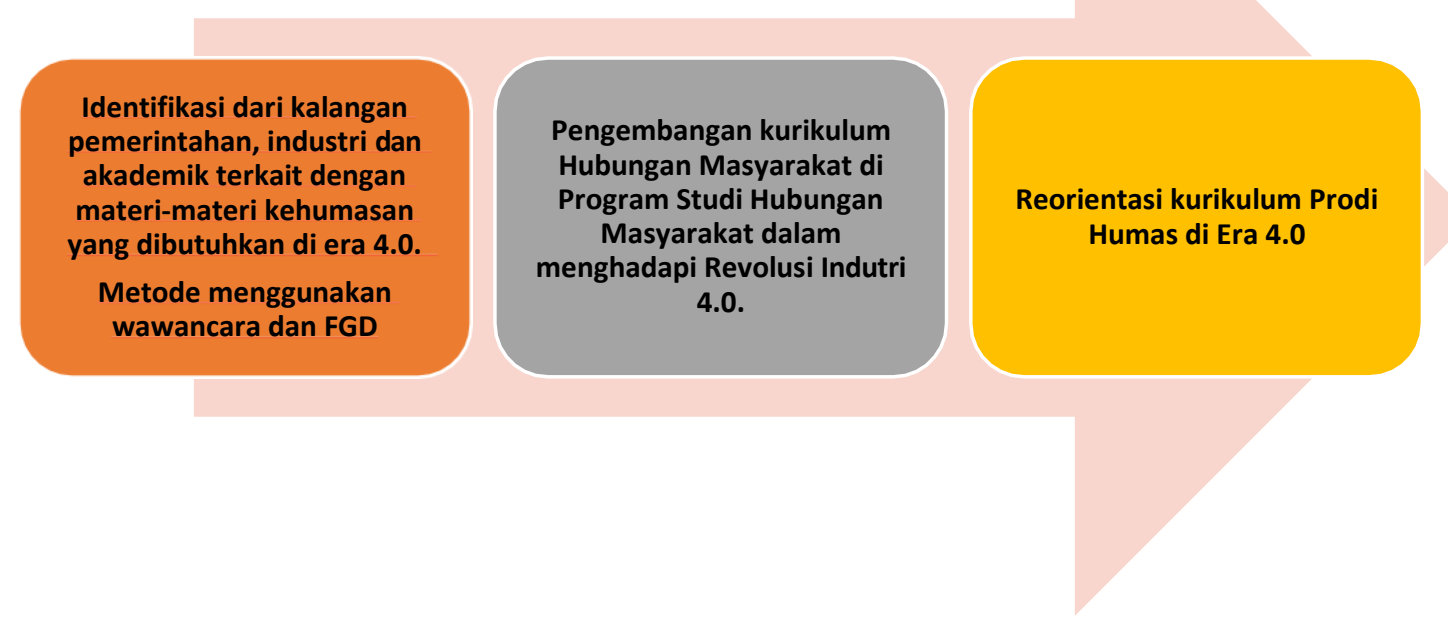

Gambar 1. Proses metode pengembangan kurikulum

\section{HASIL DAN PEMBAHASAN}

Hasil identifikasi dengan mengundang praktisi di bidang Hubungan Masyarakat, alumni dari konsentrasi Hubungan Masyarakat dan pengguna di bidang Public Relations, maka beberapa hal yang menuntut adanya penyesuaian kurikulum Program Studi Hubungan Masyarakat yang sesuai dengan perkembangan industri 4.0 yang berkaitan dengan sistem digital, antara lain;

a. Menentukan positioning program studi Hubungan Masyarakat UPN „Veteran Yogyakarta. 
b. Mengingat perkembangan teknologi dan revolusi industri 4.0 sangat berkaitan dengan digitalisasi, maka perlu membekali mahasiswa dengan adopsi teknologi, dengan memberikan pemahaman dalam mengumpulkan dan menyebarluaskan informasi.

c. Membiasakan digitalisasi di berbagai mata kuliah, tidah harus spessifik pada mata kuliah tertentu, hal ini penting untuk mendekatkan berbagai praktek yang berkaitan dengan kegiatan Hubungan Masyarakat untuk disesuaikan dengan perkembangan dan inovasi teknologi yang berkembang sangat cepat.

d. Mengingat kegiatan Hubungan Masyarakat di era digital memiliki sifat lemah kontrol, dengan pilihan akses yang lebih banyak, level yang bertingkat-tingat, dinamis dan saluran yang berubah-ubah, maka perlu menanamkan etika sejak dini sebagai upaya untuk mampu mengendalikan diri, terutama untuk mengantisipasi penyebrn hoax.

e. Social media hijacking. Humas berperan untuk melakukan kegiatan di media media untuk membentuk pasukan siber (cyber army).

f. Semakin luasnya industri dibidang Hubungan Masyarakat maka tuntutan terhadap kemampuan sumber daya manusia dal menguasai strategi Public Relations sekaligus dalam platform digital juga semakin tinggi, untuk itu perlu mengajarkan cara-cara yang dapat membantu Hubungan Masyarakat dalam menjaga reputasi perusahaan dan menghindari krisis, dengan membuat sebuah platform berbasis aplikasi atau web yang dapat membangun dialog dengan konsumen dan menggunakan cara multilevel customer interaction dan customer profiling.

g. Menanamkan kepada mahasiswa kesadaran bahwa peran Public Relations di era digital untuk mampu menjalin hubungan baik dan bekerjasama dengan publik tradisional, serta terlibat langsung dengan kelompok-kelompok yang memiliki pengaruh baru serta mampu menjalin hubungan dengan pelanggan secara langsung melalui jejaring sosial, wiki, komunitas micromedia, forum online, grup dan blog.

h. Mengingat komunikasi online itu unik yang memungkinkan organisasi dan konstituennya terlibat dalam komunikasi dua arah, maka penting juga untuk menanamkan kepada mahasiswa untuk fokus dalam berinteraksi di media online, karena dari interaksi secara online mencerminkan esensi humas digital dalam melakukan komunikasi dua arah.

\section{Pembahasan}

Pengembangan kurikulum program studi Hubungan Masyarakat dapat dilakukan dengan menggunakan berbagai pendekatan yang dapat dipilih, melibatkan berbagai pemangku kepentingan, memperhatikan landasan pengembangan kurikulum seperti faktor filosofis, psikologis, sosial, dan ilmu pengetahuan dan teknologi. Dalam mengembangkan kurikulum program studi Hubungan Masyarakat, banyak pihak harus berpartisipasi, yaitu administrator pendidikan, pakar pendidikan, pakar kurikulum, pakar sains, dosen, pemerintah, tokoh 
masyarakat dan pihak industri. Sementara mereka yang terus terlibat dalam pengembangan kurikulum termasuk administrator, praktisi, dosen, dan orang tua (Sukmadinata, 2008: 155)

Penyusunn kurikulum perlu dilakukan dengan cermat menggunakan pendekatan yang pasti. Pendekatan berikut dapat digunakan untuk mengidentifikasi konten kurikulum. Menurut Finch \& Crunkilton (1984: 140) ada lima pendekatan, yang masing-masing memiliki kekuatan dan kelemahan sebagai berikut:

1. Pendekatan filosofis menggunakan pemikiran filosofis dalam menentukan konten kurikulum. Pendekatan ini diklasifikasikan subyektif, melibatkan para ahli, pemerintah dan masyarakat. Dalam praktiknya, mungkin sulit untuk menemukan kesepakatan antara para ahli dan perencana kurikulum. Selain itu, pendekatan ini juga parsial, yang didasarkan pada pemikiran filosofis dalam pemikiran tanpa diberlakukannya hasil penelitian dan penyelarasan dengan pengembangan ilmu pengetahuan dan teknologi saat ini, kemudian juga memiliki kontradiksi karena tidak sesuai dengan industri dan perkembangan zaman.

2. Pendekatan introspektif dilakukan dengan melibatkan sekelompok dosen dan administrator pendidikan. Dalam pendekatan ini perlu ada komite penasehat kurikulum yang melibatkan komunitas bisnis dan dunia industri, tetapi kenyataan bahwa kurikulum yang dihasilkan belum tentu menjamin validitas sesuai dengan dunia kerja karena dalam membuat kurikulum tidak melibatkan industri jadi relevansinya tidak akurat.

3. Pendekatan DACUM (Developing A Curriculum) menentukan konten kurikulum dengan melibatkan terutama komunitas bisnis dan dunia industri, sedangkan keterlibatan guru dan administrator tidak terlalu dominan. Isi kurikulum memiliki relevansi yang tinggi dengan kompetensi yang cocok untuk dunia kerja, dilengkapi dengan deskripsi pekerjaan dan tugas dalam situasi nyata, kompetensi spesifik dan umum yang digunakan sebagai referensi untuk menilai hasil pembelajaran.

4. Pendekatan Fungsional dalam menentukan isi kurikulum lebih objektif karena pendekatan fungsi kerja industri dalam perencanaan kurikulum digunakan sebagai dasar, dilengkapi dengan deskripsi kinerja (kinerja), biaya dan waktu

5. Pendekatan Analisis Tugas (Task Analysis) dilakukan dengan memperhatikan pekerja di industri, konten kurikulum lebih objektif, sistematis dan menyeluruh, tetapi membutuhkan banyak waktu dan uang untuk penelitian dan pengembangan

Perkembangan kemajuan teknologi yang pesat saat ini, memasuki revolusi industri. Pengaruh ini terjadi karena tiga sebab, yaitu internet of things, virtual reality dan artificial artificial. Teknologi ini menyebabkan praktik pendidikan tinggi berubah secara mendasar. Jika di masa lalu pendidikan tinggi dilakukan sebagian besar tatap muka atau tatap muka, sekarang dengan bantuan gangguan teknologi, proses pendidikan tidak lagi perlu tatap muka tetapi online. Berkenaan dengan digitalisasi, dapat diamati bahwa praktik hubungan masyarakat telah mulai mengadopsi teknologi sehingga ada transformasi strategi dalam mencapai publik. Robert 
J. Key menjelaskan, "hubungan masyarakat di era digital membutuhkan pemahaman bagaimana konstituen utama mengumpulkan dan berbagi informasi dan kemudian mempengaruhinya pada materi pelajaran (Donald, et.al. 2008). Untuk melakukan itu diperlukan strategi yang mencakup era digital, seperti Buzzer, dan aktivis media sosial.

Praktik Hubungan Masyarakat digital sebagai proses komunikasi dua arah hadir dengan interaktivitas (Duton, 2014) yang dalam hal ini meletakkan dasar perbedaan antara posisinya dan public relations konvensional jika dilihat dari gaya komunikasi dan arus informasi. Dalam gaya komunikasi, public relations konvensional memiliki kecenderungan untuk mengontrol pesan, dengan akses terbatas dan statis. Adapun public relations digital, pesan yang dikeluarkan lemah dalam kontrol, dengan lebih banyak pilihan akses informasi, lebih banyak level, dinamis dan saluran berubah, sehingga perlu adanya pengendalian diri yang kuat untuk tidak mudah berbagi informasi tanpa dicerna terlebih dahulu.

Hubungan masyarakat di era digital membutuhkan pemahaman bagaimana konstituen utama mengumpulkan dan berbagi informasi dan kemudian mempengaruhinya pada materi pelajaran (Donald, 2008). Untuk melakukan itu diperlukan strategi yang mencakup era digital. "Sebagai contoh, sebuah perusahaan dapat melakukan beberapa strategi hubungan masyarakat digital melalui penyesuaian dengan tradisi online, termasuk mengantisipasi penyebaran tipuan dan pembajakan media sosial. Peran hubungan masyarakat di sini dapat dilakukan dengan kegiatan media sosial seperti pembentukan cyber pasukan.

Penanaman kesadaran bahwa peran hubungan masyarakat digital dalam kasus ini tidak hanya dituntut untuk dapat membangun hubungan baik dan bekerja sama dengan publik tradisional, tetapi juga untuk secara langsung terlibat dengan kelompok influencer baru yang tidak disengaja, dalam membangun hubungan dengan pelanggan secara langsung melalui jejaring sosial, wiki, komunitas Macromedia, forum online, grup, dan blog (Solis dan Breakenridge, 2009). Dengan demikian, di antara semua alat komunikasi yang tersedia untuk praktisi PR, komunikasi online secara unik dilengkapi untuk memungkinkan organisasi dan konstituen mereka untuk terlibat dalam komunikasi dua arah (Hirsch, 2018).

Sederhananya, reorientasi kurikulum kemudian diterjemahkan sebagai bahan kuliah menyesuaikan dengan perkembangan revolusi industri 4.0. Sebagai contoh, bagaimana mahasiswa tahu tentang penggunaan big data dalam proses perkuliahan? Penggunaan big data tentu saja tidak hanya terbatas pada pengetahuan, tetapi mahasiswa juga akan diminta untuk dapat membaca, menganalisis dan mengoptimalkan kegunaan lain. "Bisa juga pemrograman, pengkodean, pengembangan web, dan keterampilan lain yang diperlukan untuk menjadi kompetitif di era revolusi industri 4.0. Ketika mahasiswa dapat dengan bebas mendapatkan materi kuliah secara virtual, dosen masih memainkan peran penting sebagai fasilitator. Dosen harus dapat menantang mahaasiswa untuk mengoptimalkan penggunaan big data dan media online dalam perkuliahan. 


\section{SIMPULAN}

Pada dasarnya peran hubungan masyarakat atau Public Relations di era 4.0 adalah memiliki kemampuan teknis maupun kemampuan praktis dalam menggunakan berbagai perangkat media secara global, digital dan kreatif. Transformasi praktik hubungan masyarakat digital tidak terlepas terhadap kontribusi industri 4.0 melalui penetrasi teknologi, sehingga dengan perubahan berbagai cara dalam berbagai kegiatan Public Relations digital, itu tidak serta merta menghilangkan jejak pada cara public relations konvensional, namun, pada prinsipnya semua berkontribusi untuk saling melengkapi walaupun ada yang mendominasi dan membutuhkan analisis terlebih dahulu jika ingin menerapkan salah satu strategi.

Pentingnya fokus pada alat online ini mencerminkan esensi dari kurikulum hubungan masyarakat di era digital sebagai proses komunikasi dua arah yang hadir dengan interaktivitas. Transformasi praktik hubungan masyarakat di era digital tidak kebal terhadap kontribusi industri 4.0 melalui penetrasi teknologi. Dengan perubahan cara dalam hal aktivitas hubungan masyarakat digital, itu tidak serta merta menghilangkan jejak dalam cara public relations yang konvensional. Sebagai bagian dari studi ilmu komunikasi, hubungan masyarakat digital tentu perlu dikelola dengan baik dan memperhatikan aspek etika dan kontribusi praktis sehingga dapat diimplementasikan dalam kehidupan masyarakat.

\section{DAFTAR PUSTAKA}

Acatech. (2014). Recommendations for Implementing the 8 Strategic Initiative Industri4.0. Frankfurt: National academy of Science and Engineering.

Cutlip, S. M. (2011). Effective Public Relations,9th ed. Jakarta: Indonesia Kencana.

DiStaso, M., Mc.Corkindale, T., \& Wright, D. (2011). How Public Relations Executives Perceive and Measure the Impact of Social Media in Their Organizations. Public Relations Review, 37(3), 325-328. http://dx.doi.org/10.1016/j.pubrev.2011.06.005

Donald K. \& Hinson, Michelle D. Wright (2008) How Blogs and Social Media are Changing Public Relations and the Way it is Practiced, Blogs \& Social Media - Public Relations Journal, vol. 2, no. 2, pp. 1-21, Spring.

Dutton, William H (2014) Putting things to work: Social and policy challenges for the Internet of things. Info, vol. 16, no. 3, pp. 1-21, Sep. 2014.

Finch Curtis.R \& Crunkilton. (1984). Curriculum development in vocational and technical education: Planning, content, and implementation. Sidney. Allyn and Bacon Inc.

Hirsch, P. B. (2018). Clicks or commitment: activism in the age of social media. (pp.55-58) Journal of Business Strategy.

Mozorov, E (2009) From slacktivism to activism, Foreign policy (pp. 43-50)

Pascall, T. (2019). innovation industri 4-0. Retrieved from disruptionhub.com https://disruptionhub.com/innovationindustri-4-0/

Robert, L. a. (2008). Organizations and Public Policy Challenges (pp.400-412) Journal strategic: Issues Management, 
Seitel, F. P. (2014). The Practice of Public Relations. Jakarta: Erlangga.

Smith, R. (2005). The Cure and Wishful Thinking. New York: Elsevier.

Smith, Ronald D (2004). Strategic Planning for Public Relations. London: Lawrence Erlbaum Associate

Solis, Brian and Deirdre Breakenridge (2009) Putting the Public Back in Public Relations: How Social Media Is Reinventing the Aging Business of PR. UK: FT Press.

Sukmadinata, Nana S. (2008). Pengembangan kurikulum: Teori dan Praktek. Bandung: Remaja Rosdakarya.

Szutowski, D. (2018). Innovation Source, Advancement Stage and Company Stock Returns. The Service Industries Journal, 1-18. http://dx.doi.org/ 10.1080/ 02642069.2018.1450869

Veil, S., Reno, J., Freihaut, R., \& Oldham, J. (2015). Online Activists vs. Kraft Foods: A Case of Social Media Hijacking. Public Relations Review, 41(1), 103-108. http://dx.doi.org/10.1016/j.pubrev.2014.11.017

Vermesan, O. a. (2013). Internet of Things Strategic: Research and Innovation Agenda, 1st ed. Aalborg, Denmark: River Publishers. 